\title{
Range extension of Christisonia scortechinii from mainland Southeast Asia into Borneo, and notes on the distinction between Aeginetia and Christisonia (Orobanchaceae)
}

Antony van der Ent ${ }^{1,2}$ and K. M. Wong ${ }^{3 *}$

\begin{abstract}
Background: Christisonia is a little-documented and poorly studied root-parasitic genus in the Orobanchaceae occurring in India, China, Indochina and part of the Malesian region. Recent collection of a Christisonia taxon in Kinabalu Park in Sabah, Borneo, taxonomically identical to earlier Sabah collections that have hitherto not been recorded in the literature, led to an assessment of the taxonomic identity of the species against Christisonia scortechinii, C. siamensis, C. sinensis and related species.

Results: Some taxa in China, Indochina, the Malay Peninsula, and the Philippines are morphologically identical to the Borneo taxon except in the number of calyx lobes, but differ by several distinctive characters from other well-distinguished species in the region. Studies of dried herbarium specimens, augmented by photographic images of different stages of fresh flowering material and a scrutiny of available descriptions confirmed that the calyx has two primary lobes in the bud that may separate into 3-5 portions, giving a variable number of apparent lobes in specimen material collected at different localities. This new scrutiny of the calyx also permitted an improved description of the calyx differences that separate Christisonia and the closely related Aeginetia, which have not been clearly elucidated in the past.

Conclusions: Christisonia scortechinii Prain (Orobanchaceae), the only species that was described as having an initially spathaceous calyx among species of this root-parasitic genus, is newly recorded for Borneo (including Kinabalu Park, where its presence has been overlooked). The range of the species in mainland Southeast Asia, previously extended from Peninsular Malaysia to Thailand and Vietnam, is here further extended to Laos and China. Christisonia wightii Elmer (relevant to the Philippines) and C. sinensis Beck (China) are reduced to synonymy.
\end{abstract}

Keywords: Aeginetia, Borneo, China, Christisonia, Kinabalu, Laos, New record, Orobanchaceae, Philippines, Ultramafics

\section{Background}

The root-parasitic genus Christisonia Gardn. has ca. 20 species distributed from India to China and the Malay Peninsula (Parnell 2001, 2008), Philippines, SW Celebes and Flores (Van Steenis 1967). Christisonia has hitherto

\footnotetext{
*Correspondence: wkm2000@gmail.com

3 Singapore Botanic Gardens, 1 Cluny Road, Singapore 259569, Singapore Full list of author information is available at the end of the article
}

not been documented for Borneo Island, in spite of preexisting collections, although the closely related Aeginetia L. is recorded there (Beaman and Anderson 2004; under Scrophulariaceae). Both Christisonia (Quisumbing 1940) and Aeginetia (Kusano 1903, Lee and Goseco 1932) have been reported to parasitize the roots of sugarcane crops. In nature, Christisonia is also a root-parasite on other grasses, including bamboos (Barlow 1982; Parnell 2001), and other plant families, including Acanthaceae 
(Nandikar et al. 2013) and Vitaceae (Benniamin et al. 2012).

Christisonia and Aeginetia are resolved in the same clade, within the tribe Buchnereae, in the general molecular phylogeny of the Orobanchaceae (McNeal et al. 2013). However, a closer study of the phylogenetic relationship between these two genera with adequate taxon sampling is still elusive. Christisonia species have been distinguished by their distinctly lobed calyx from Aeginetia, also a root-parasitic genus, which has spatheate calyx (Parnell 2001). Prain (1904) had, however, also described the calyx of the Malayan C. scortechinii as "spathaceous rupturing into usually 2 , occasionally $3-4$ lobes in the fully opened flower", so causing uncertainty if the spatheate calyx of Aeginetia is a consistent character for distinguishing it from Christisonia (Parnell et al. 2014). Nevertheless, the presence of a covering of colourless slime over Christisonia flower buds (Fig. 1a) seems to provide another consistent distinction from Aeginetia, in which this slime is absent (Parnell et al. 2014). Also, most Christisonia spp. have largely white corollas, and most Aeginetia spp. lilac, purple, red or yellow corollas, although this is not mutually exclusive and a purplish corolla form has been reported for C. scortechinii (Yong 1989) (Fig. 1d) and species such as A. indica also have white corolla forms (Parnell 2012). Another general difference is that Christisonia flowers are typically on short pedicels borne on short or obscure stems that do not protrude much from the ground level, whereas Aeginetia species often have taller stems $10-40 \mathrm{~cm}$ long that carry the flowers clearly above ground level.

More recently, the distribution of several Christisonia species has become better documented. For example, $C$. siamensis Craib, once thought to be endemic to Thailand
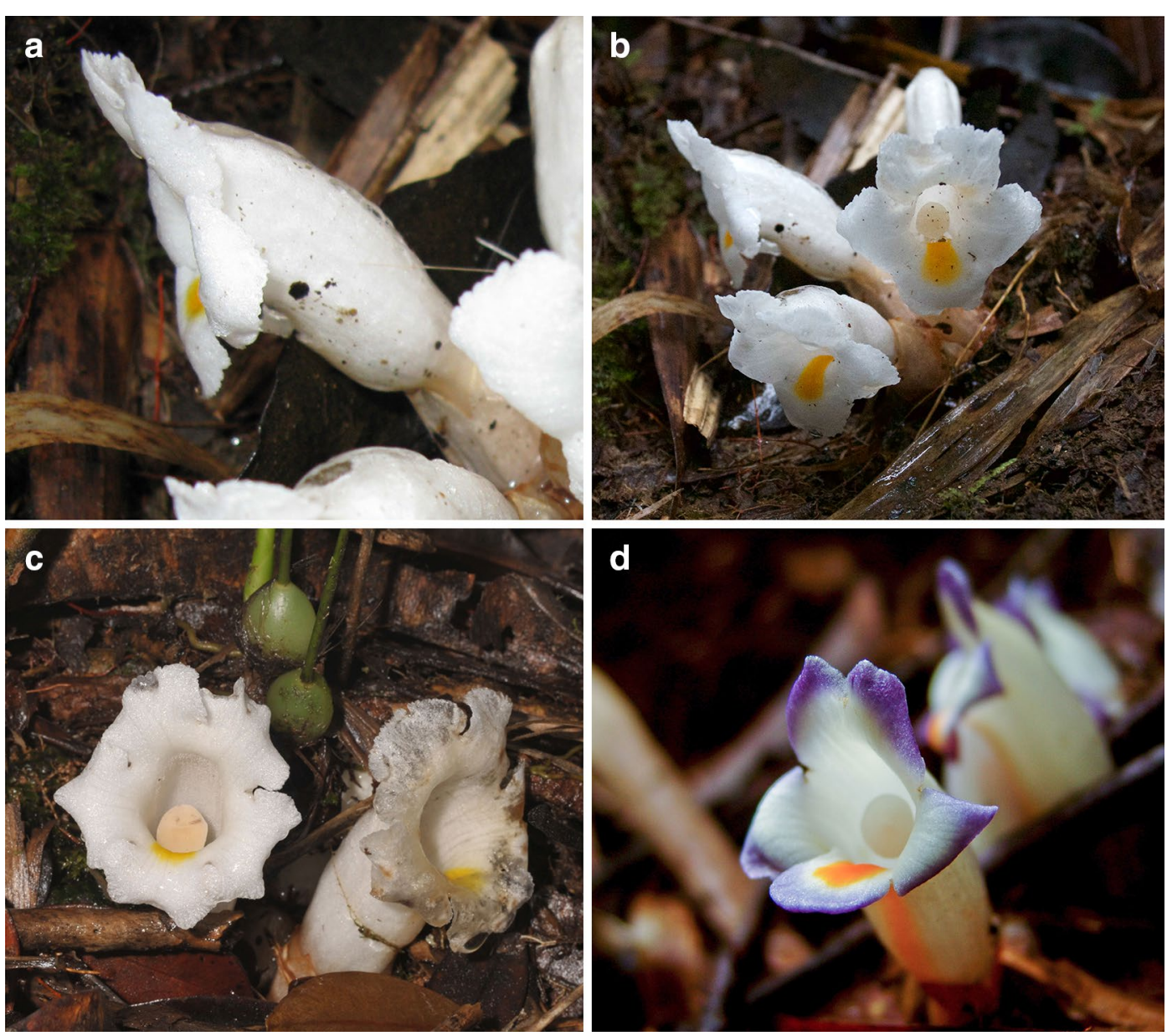

Fig. 1 Flowering material of Christisonia scortechinii from Sabah (Kinabalu Park) (a-c) and a purple-tinged variant from Peninsular Malaysia (Sungei Wi, Cameron Highlands) (d). a Side view of flower showing the transparent slime covering. $\mathbf{b}$ Cluster of fresh flowers with short calyx lobes and a yellow band on the lip that continues down into the corolla tube. c Open flowers, with one showing the peltate discoid stigma in the throat. $\mathbf{d}$ Christisonia with unusual purple-tinged corolla. Photos: Sukaibin Sumail (a), A. van der Ent (b, d) and R. van Vugt (c) 
(Parnell 2001) has been documented in Nagaland, NE India (Benniamin et al. 2012) and SW China (Tan 2013). Nevertheless, the identification of these root-parasites, the flowers of which are delicate and difficult to preserve (spirit collections are essential), remains challenging. Comparatively few collections of the various species and the poor state of preservation of key reference specimens of earlier documented species hamper comparison and reliable identification (Parnell 2001; Parnell et al. 2014). Only in a number of cases where photographic images of sufficient quantity are available can we elucidate the morphology and variation. This, fortunately, is becoming the case as amateur and professional botanists make their images more readily available on the World Wide Web.

This paper formally records Christisonia for Borneo through specimens collected recently from Kinabalu Park by Antony van der Ent (Fig. 1a-c), which began this investigation, as well as previous collections from there and elsewhere in Sabah.

\section{Methods}

Herbarium material of Christisonia for Borneo was studied at the Singapore Herbarium (SING) and the Sabah Parks Herbarium (SNP), and through images on JStor for the Global Plants Initiative, the latter including material from $\mathrm{K}$ and WU; herbarium acronyms used follow Thiers (2015). The SNP specimens collected by A. van der Ent in Kinabalu Park were preserved in FAA mixture. Photographic images of different stages of fresh flowering material taken by A. van der Ent and colleagues or which were available from various internet sources (as respectively acknowledged below) aided the interpretation of floral structures and development, especially that of the calyx.

\section{Results and discussion}

\section{Christisonia newly recorded for Borneo}

Cedric E. Carr, better known for his orchid collecting (Kiew 2003), was apparently the first person to collect a Christisonia from Mount Kinabalu and Borneo, although this was never recorded in any publication, including the recently completed Plants of Mount Kinabalu where Beaman and Anderson (2004) had missed Carr's number SFN 26457 of this taxon in the Singapore Herbarium. Carr's locality was the Kinataki River (below the famous Marai Parai spur) at around $1400 \mathrm{~m}$ on the western flank of Mount Kinabalu.

Christisonia scortechinii (Fig. 1) was recorded by Antony van der Ent from two localities inside Kinabalu Park, the first at Marai Parai (near the Kinataki River where also Carr collected this species on Mount Kinabalu over 80 years earlier), and the second on Mount Tambuyukon in the north of Kinabalu Park. Both localities sit at 1500-1800 $\mathrm{m}$ asl in dense montane cloud forest on ultramafic soils and have remarkably similar vegetation in aspect and composition. Specimens were collected only from the Marai Parai site on Mount Kinabalu, while the Mount Tambuyukon occurrences were documented with photographs.

The Christisonia is root-parasitic on the bamboo Racemobambus gibbsiae (Poaceae) which is abundant at both sites. The parasitic plants occur as scattered typically "clumped" individuals in the permanently moist humusrich soil. It appears to be flowering year-round as it has been recorded on a number of occasions during fieldwork. The Marai Parai site is a steep slope along the Kinataki River below the famed spur that is the type-locality for many of Kinabalu's enigmatic plant species, such as Nepenthes rajah and $N$. edwardsiana (Nepenthaceae). Mount Tambuyukon (2579 $\mathrm{m} \mathrm{asl}$ ) is the third highest mountain on the island of Borneo and the highest ultramafic mountain in the region. The vegetation on this mountain ranges from tall mixed dipterocarp forest on the foot slopes to stunted graminoid scrub near the summit. The Christisonia occurs between Musang Camp and General Camp on the east flank roughly $400 \mathrm{~m}$ below the summit.

Voucher material for C. scortechinii recorded on Mount Kinabalu include the following:

SABAH, Ranau, Mount Kinabalu, Kinataki River, ca. $4500 \mathrm{ft}(1370 \mathrm{~m}), 7$ Mar. 1933, C.E. Carr SFN 26457 (SING), Marai Parai, near Kinataki River, 1630 m, 31 Mar. 2011, A. van der Ent, S. Sumail E R.M. Karim SNP 23658 (SNP).

Christisonia scortechinii is also known from elsewhere in Sabah, also on ultramafic soils:

SABAH, Kinabatangan district. Telupid, Bukit Tawai, near summit, 1 Sep. 1999, R. Kiew RK 4817 (SING), Sungai Ruku-Ruku Forest Reserve, 3 Sep. 1999, Ali Ibrahim E R. Kiew AI 540 (SING).

The flora of Kinabalu Park is the richest globally in terms of the number of plant species per unit area with more than 5500 taxa recorded from an area roughly $1200 \mathrm{~km}^{2}$ in extent (Beaman 2005, Van der Ent unpublished). Plants with alternative metabolism or nutrientacquisition strategies in Kinabalu Park include insect and/or rodent scat trapping ('carnivorous') plants (Nepenthaceae, Droseraceae, Lentibulariaceae), myrmecophytes (Rubiaceae: Hydnophytum, Myrmecodia), myco-heterotrophic ('saprophytic') plants (mainly Burmanniaceae, Orchidaceae, Triuridaceae), and parasitic plants (principally Loranthaceae and Rafflesiaceae). Most of the hemi-parasitic plants (those that have an active photosynthesis system) in Kinabalu Park are in the order Santalales represented by approximately 60 species predominantly in the families Loranthaceae and Santalaceae (Beaman and Anderson 2004). Apart from 
the newly recorded Christisonia, holo-parasitic plants (which derive all carbohydrates exclusively from the host) include three species of Balanophora (B. lowii, $B$. reflexa and B. papuana) (Balanophoraceae), one species of Rhizanthes ( $R$. lowii), one species of Mitrastema ( $M$. yamamotoi) and two species of Rafflesia (R. keithii and $R$. pricei) (the latter three genera in Rafflesiaceae).

The local occurrence of ultramafic soils has been suggested as a driving force for speciation, in combination with recent uprising of the Mount Kinabalu Massif, isolation and other factors (Beaman and Beaman 1990). Soils developed from ultramafic (often called 'serpentine' by botanists and ecologists) bedrock induce an edaphic filter on the vegetation that includes nutrient deficiencies, major cation imbalances and metal toxicities (Proctor 2003). As a consequence, ultramafic vegetation in Sabah is often of lower stature, with distinct species composition compared to mixed dipterocarp forest on sedimentary soils. Ultramafic habitats in Borneo are known to harbour a multitude of rare and localised plant species (Wong 1998). Although ultramafic host a number of endemic taxonomic entities that could be evolutionarily derived from closely related taxa from adjacent environments, so-called "neo-endemics" (Van der Ent et al. 2014, 2015), we could not detect any consistent morphological differences between the C. scortechinii from the Sabah ultramafic sites and that from elsewhere.

\section{Comparing Sabah Christisonia material with closely related} taxa

At the outset we were able to determine that the Sabah taxon (Fig. 1a-c) is most related to C. scortechinii Prain, C. siamensis Craib and C. sinensis Beck, in that all these typically or frequently have glabrous white corollas with a single yellow patch that runs from the base of the lip to within the throat and peltate stigmas.

\section{Christisonia scortechinii}

An unnumbered collection of $C$. scortechinii at Kew (K000899781) represents potential type material against which to interpret the species in its original Malay Peninsula provenance, given the type sheet bearing Scortechini's number 2121 at Calcutta is in poor condition (Parnell et al. 2014). But even on the Kew sheet, it is difficult to make out intact calyx lobes and verify other characters because the dried material is in poor condition and mounted on a sheet. Thus the interpretation of C. scortechinii has depended in large part on direct visual assessment of fresh material from Peninsular Malaysia (Fig. 1d), other herbarium material available (see below), the original description by Prain (1904), as well as the sketch in Henderson (1954) and available photographic images, such as in http://www.parasiticplants.siu.edu/
Orobanchaceae/images/Christisonia1.jpg and http:// www.parasiticplants.siu.edu/Orobanchaceae/images/ Christisonia3.jpg.

\section{Christisonia siamensis}

Christisonia siamensis is well distinguished from $C$. scortechinii, C. sinensis and the Sabah taxon in frequently having violet-purplish corolla coloration and a distinct hair tuft at the insertion of the anther that obstructs the corolla throat (Parnell et al. 2014), which is absent in the latter three taxa, which have quite glabrous filaments.

\section{Christisonia sinensis}

Christisonia sinensis, found in SW and SE China, was reduced to the synonymy of $C$. hookeri C.B.Clarke ex Hook. in the Flora of China (Zhang and Tzvelev 1998). However this may not be justified because, as pointed out by Parnell et al. (2014), the stigma was described as unequally bilobed in the type description of $C$. hookeri (Hooker 1885) whereas the Flora of China treatment describes a discoid stigma 4-6 $\mathrm{mm}$ in diameter, which fits the peltate stigma illustrated in photographic images from Chinese material, as shown in Fig. 2, for example.

Although Parnell et al. (2014) expressed doubt that Chinese material (with peltate stigmas) had been correctly identified as $C$. hookeri (described as having bilobed stigmas), they did not comment on the status of the name $C$. sinensis.

\section{Identification of the Sabah Christisonia}

Table 1 compares a number of characters among the Sabah taxon, C. scortechinii, C. siamensis and C. sinensis, as well as $C$. calcarata and $C$. hookeri, both of which are clearly differentiated from the others by their bilobed stigmas. Other very conspicuous and consistent characters also help differentiate consistently recognised species in Table 1, such as the slender pedicellate flowers of C. calcarata; a distinct hair tuft at the anther insertion in $C$. siamensis; and the densely pubescent corolla in $C$. calcarata. It would appear that while the predominantly white corolla is also important, occasional violet or purplish tinges do occur. The single band of yellow marking the lip and down into the corolla throat in C. scortechinii (Fig. 1), C. siamensis and C. sinensis (Fig. 2a) also distinguishes these species from $C$. calcarata, where the entire throat is yellow. These provide an idea of various specialised characters that clearly distinguish species.

It can be seen from Table 1 that, while C. calcarata, $C$. hookeri and $C$. siamensis are immediately distinguished from the rest as stated above, C. scortechinii, C. sinensis and the Sabah taxon remain rather similar, including in the variable number of calyx lobes, a character that had caused much hesitation in deciding whether or not $C$. 

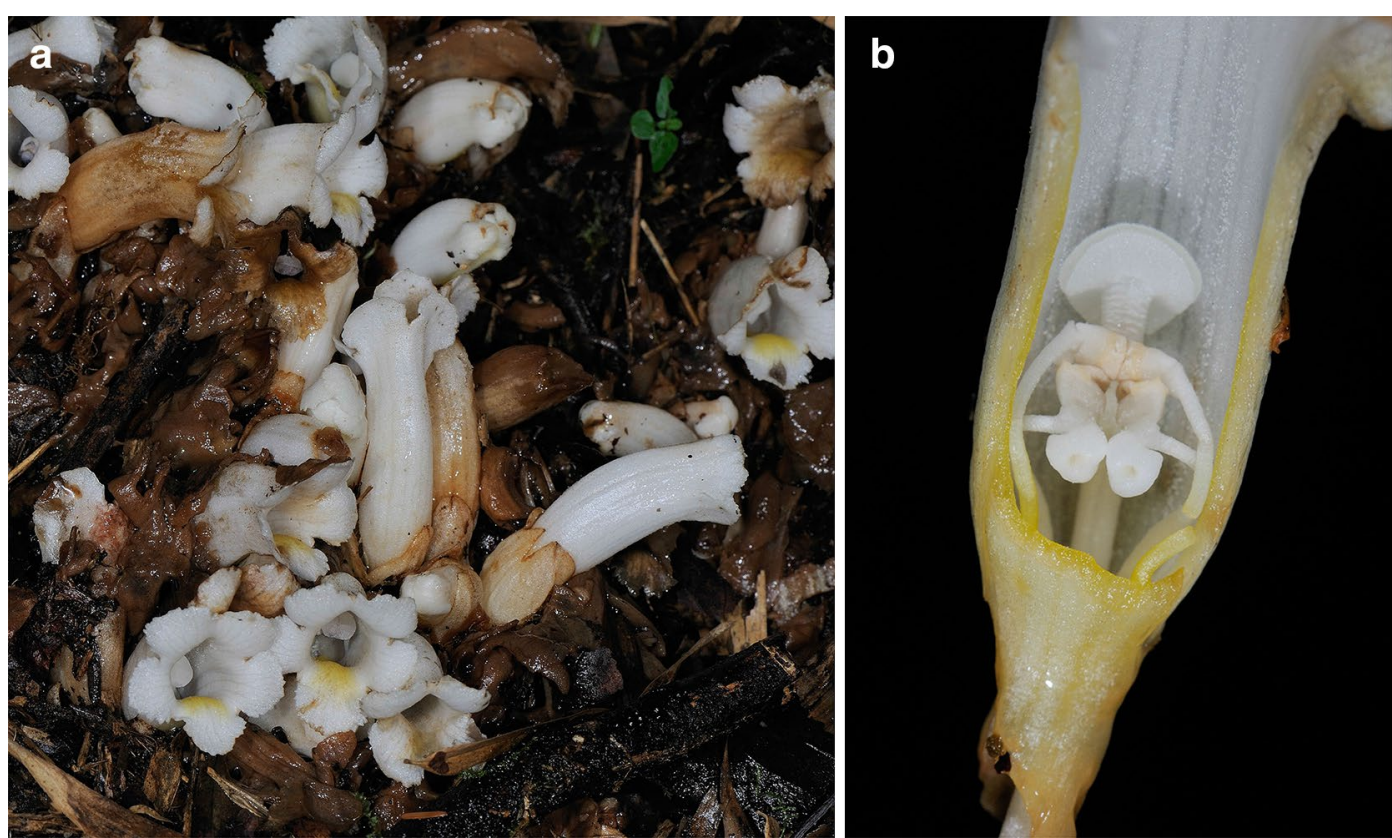

Fig. 2 Christisonia sinensis from Chinese material. a Flowers, with slime over young buds and (center-right) suturing of calyx lobes that incompletely separate. $\mathbf{b}$ Corolla cut open to show the peltate discoid stigma and two pairs of stamens; in the shorter stamens, the anther appendage has a short acute projection on the dorsal side. (Reproduced with the kind permission of Ming-I Weng, from: https://www.flickr.com/photos/mingiweng/4927639081/; http://www.flickriver.com/photos/mingiweng/4928219216/)

scortechinii from the type provenance (Peninsular Malaysia) and other provenances in Thailand and Vietnam should be conspecific.

In order to understand the nature of the calyx lobes better, we examined specimen material of $C$. scortechinii from Peninsular Malaysia (the type provenance) to see if they agreed with the original description of Prain (1904); and both dried preserved material (mostly expected to be in poor condition) and photographic images that could assist in interpreting this character for other similar taxa in China (as C. sinensis Beck or C. hookeri sensu Zhang \& Tzvelev, non (C.B.Clarke) Hook.), Vietnam, and Thailand.

For material from the type provenance of C. scortechinii, the diagram given by Henderson (Henderson 1954: 335, Fig. 317) clearly shows calyces with 2 or 3 lobes. Earlier, Ridley (1923) had also described "Calyx spathaceous splitting into 2-4 lobes...", which is not different from what Prain (1904) stated. We also studied the following material:

PENINSULAR MALAYSIA, Perak, Bukit Kinta Forest Reserve, 28 Apr. 1987, R. Kiew RK 2583 (KEP, SING); Perak, Ulu Batang Padang, no date, Ridley 13693 (SING); Selangor, Ginting Simpah, top of pass, ca. $2000 \mathrm{ft}(609 \mathrm{~m})$, 20 Sep. 1947, J. Reid s.n. (SING).

In fact, Reid's specimen had helped the description in Henderson (1954), as evident from his letter to Henderson pasted on the specimen, which, among other things, gave the occurrence of the species as "sparsely distributed in small localised patches at moderate altitudes." All five calyces of young as well as open flowers on the Reid specimen sheet show 2 lobes; one young bud shows a single deep suturing across the top of the calyx (implying two lobes from a younger stage). The Ridley specimen has only one 'good' flower in the packet showing clearly two main lobes, each with a short median tear (which can be expected to give at least four lobes perceptible at a later stage). The Kiew specimen shows 2, 3, 4, or 5 calyx lobes, unequal in width as if from tears rather than from preformed equivalent calyx members.

Christisonia sinensis is very similar to C. scortechinii, including some Thai and Vietnamese (Central Mountains Region) material that was identified as the latter species (Parnell et al. 2014). The wider concept of C. scortechinii (Parnell et al. 2014) accepted that the calyx may be spatheate in the bud but becoming 2-4(-5)-lobed. Although herbarium material for the genus is admittedly poor (Parnell et al. 2014), the type of C. sinensis, Handel-Mazzetti 9595, Yunnan, 2850 m, 31 July 1916 (WU), clearly shows the short thick pedicels, short-lobed calyces and peltate stigmas that accord with the images of material from China as well as the Thai and Vietnam material mentioned. Moreover, the type also includes flowers where the calyx is variably 2-3-lobed or even 5-lobed, indicating that the calyx in $C$. sinensis does not always part into 5 lobes. 


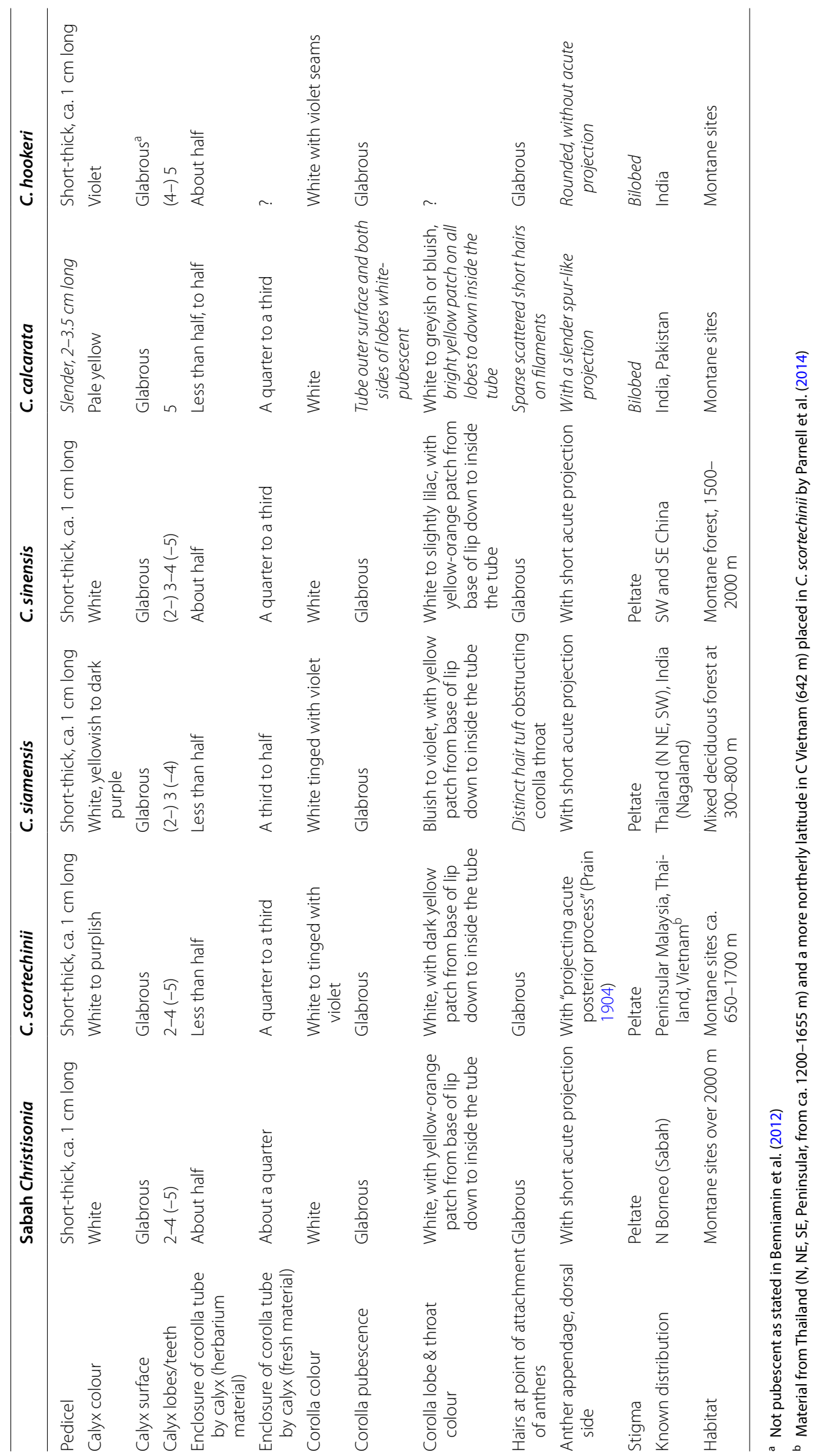


Prain (1904) described that the lower pair of stamens of C. scortechinii had "a projecting acute posterior process", and C. sinensis material from China, as well as Thai and Vietnam material ascribed to C. scortechinii in Parnell et al. (2014), also develop a small acute or conical projection on the anther appendage. This can be seen in Chinese material (Fig. 2b) as well as the Sabah material (Fig. 3b). These vary slightly in prominence but are instantly distinguished from the slender elongate, spurlike projection from the dorsal side of the anther appendage developing in another species, $C$. calcarata.

Fresh Chinese material from Taiwan referable to C. sinensis beginning with two calyx lobes that sustain visible apical tears can be seen in images from the website: https://www. flickr.com/photos/mingiweng/4928220164/ and examples of calyx tearing into 3-5 lobes can be seen in: http://www. plant.csdb.cn/details?guid=photo:cfh@5c7f74b1-31df4c72-a872-a2d446a8fa22.

Incompletely separating calyx lobes are clearly seen in Fig. 2a.

Even more instructive, Chinese (Taiwan) material showing a bud calyx with only a small apical opening, and other calyces tearing irregularly into several lobes are obvious in: http://blog.xuite.net/bibibear599/ twblog/137870776.

Likewise, the variable number of calyx lobes that can be seen in web-images of fresh material from mainland China, Vietnam and Thailand has been discussed in detail by Parnell et al. (2014), including their Figs. 1c and $2 \mathrm{a}$. Vietnam material with calyx tearing into 5 or more lobes is also available in: https://www.flickr.com/photos/ biodivn/14351717859/.

To these we wish only to add a new record of the same taxon for Laos:

LAOS, Houa Phan Province, Vieng Thong District, Nam Et-Phou Louey Natural Protected Area, Nam Et side, near Ban Phon Song, $20^{\circ} 20^{\prime} 46^{\prime \prime} \mathrm{N}, 103^{\circ} 22^{\prime} 04^{\prime \prime} \mathrm{E}, 953 \mathrm{~m}, 8$ Jun. 2013, J. Leong-Skornickova, M. Rodda, Aung Thame, U. Souvannakhoummane, K. Phoutthavong, M. Norsaengsri $\mathcal{E}$ S. Sangvirotjanapat JLS 2407 (E, P, QBG, SING).

Most calyces from this specimen are torn, but one clearly shows 2 lobes, another in bud has the calyx showing only a single small median tear (or slit).

These observations imply that there is no consistent difference in the number of calyx lobes between $C$. scortechinii and C. sinensis, supporting a key premise on which Parnell et al. (2014) based their extension of the range of $C$. scortechinii to include sites in Thailand and Vietnam. Although for some other species, e.g., C. calcar$a t a$, the number of calyx lobes seems evenly formed and are consistently 5 in number, for other species such as $C$. scortechinii and $C$. sinensis, there is generally a variable number of calyx lobes. It would seem that the basic condition representative of the latter two taxa is a basically 2-lobed calyx, where the lobes are fused to only slightly separated in the bud stage, later separating into two clear

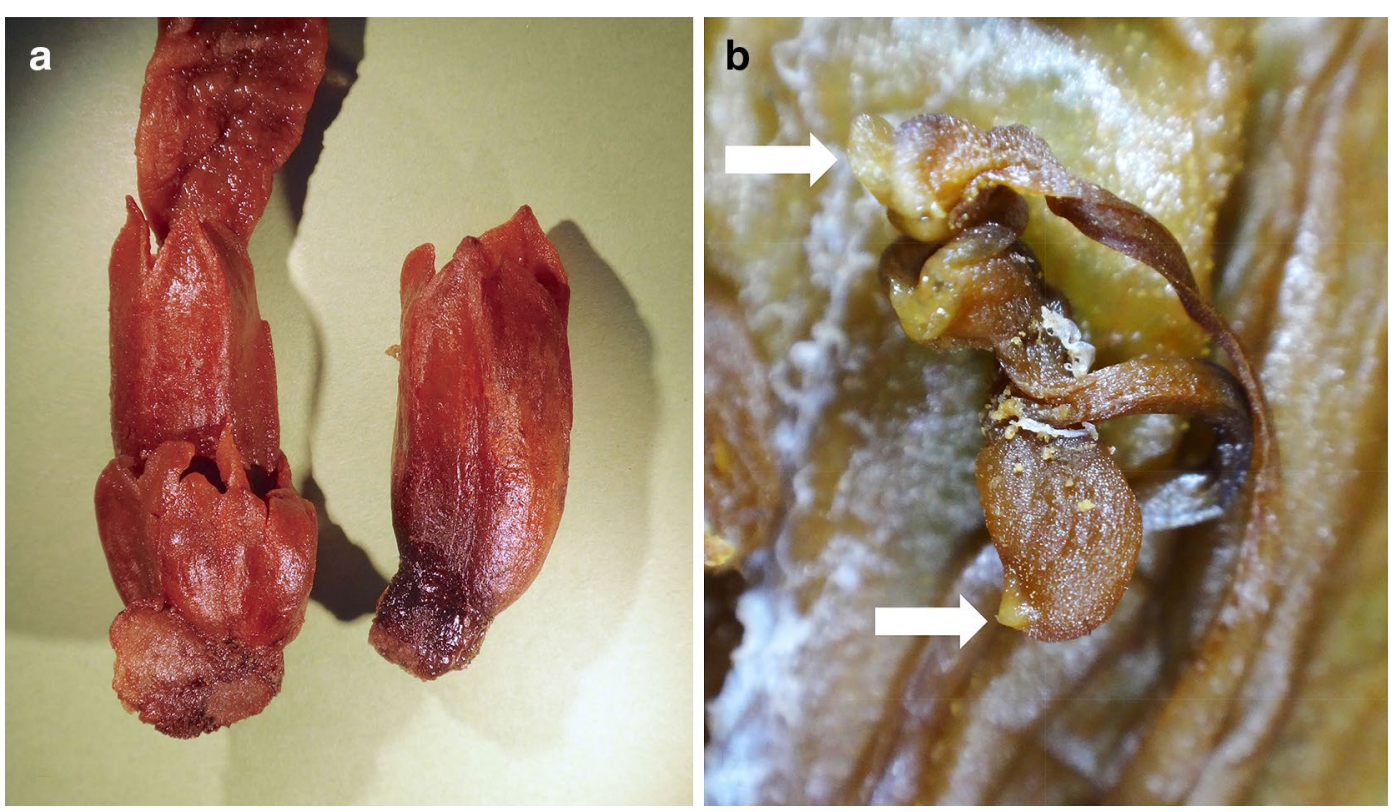

Fig. 3 Christisonia scortechinii from Kinabalu Park, showing calyces separating into 3 or more lobes (a) and detail of one set of stamens (b) showing anther of longer stamen (upper arrow) close to the anther of shorter stamen, which has a dorsal lobe with an acute process at its tip (lower arrow). From spirit-preserved material of Van der Ent et al. SNP 23658 (SNP) 
lobes, each of which can sustain a secondary median tear, in all giving 2, 3, or 4 lobes (as was recorded by Prain for typical C. scortechinii and not authoritatively recorded for C. sinensis), or even 5 lobes (as common in and recorded for $C$. sinensis and some material from Vietnam and Thailand). Other distinct species may also show a similar calyx character, e.g., the painting of Christisonia thwaitesii Trimen by H. DeAlwis in Trimen (1893-1898), t. 69, depicts calyces with 2 lobes, 3 lobes and irregularly tearing lobes: http://plantillustrations.org/illustration. php?id_illustration $=157328 \&$ mobile $=0$.

In fact, the description of the calyx by Trimen (1895: 263) of $C$. thwaitesii is not only accurate but also describes the condition in C. scortechinii: “...quite closed in the bud (which is beaked), deeply 2-lipped, the lips irregularly or faintly 2 - and 3-toothed...."

The material from Sabah also amply displays the same condition of basically two calyx lobes that may further divide (tear) to give 2,3 , or 4 , even 5 lobes. Carr's material is rather well preserved, with one calyx clearly showing division into two main lobes, and another having two main lobes with apical tears. The recent material collected by van der Ent and colleagues also shows 3-4 calyx lobes (Fig. 3a).

\section{A wider geographical range for Christisonia scortechinii}

The impression from descriptions, dried herbarium specimens and photographic images of different stages of fresh flowering material in C. scortechinii, C. sinensis and the Sabah taxon is that the calyx is basically composed of two lobes that slightly to mostly cohere in the young flower bud, with an apical slit along which the main calyx lobes part and through which the corolla protrudes. In summary, there seem to be no significant differences between C. scortechinii and C. sinensis and our Sabah taxon. The Malayan name would take precedence.

Christisonia scortechinii is probably also distributed in the Philippines. Images by Leonardo L. Co identified as C. wightii Elmer from the Sierra Madre Mountain Range, Cagayan Province, Luzon Island, and the (ultramafic) Mount Victoria massif on Palawan Island (http://www. philippineplants.org/Families/Orobanchaceae.html), both show Christisonia flowers with a peltate discoid stigma, and appear to be the same as C. scortechinii. Christisonia wightii Elmer, described based on material from Negros, was the only species described for the Philippines, and of which the type is not found and probably not extant (likely at PNH and destroyed during WWII). Of the type specimen Elmer 9510, Elmer (1915) says "A specimen was however sent...to Dr. Ridley [italics his] for determination and who pronounced it a species of Christisonia." This collection is not at SING. We have examined the following material, however most calyces are fragmented:
PHILIPPINES, Mindanao, Camp Keelthler, Lake Loamao, Apr. 1907, M.S. Clemens, s.n. (SING).

Elmer (1915) described the stigma as "composed of 2 broad and fleshy lobes", which differs from the clearly peltate discoid stigma in C. scortechinii, otherwise the details he gives do not vary specially from the characters of $C$. scortechinii or C. sinensis. We regard that Elmer's description of the stigma may have been inaccurate and consider that his species is likely the same as C. scortechinii.

The material from China, Vietnam and Thailand (as detailed by Parnell et al. 2014), Laos, Peninsular Malaysia (Prain 1904; Ridley 1923) and Borneo (Sabah), probably also that from the Philippines which we identify as C. scortechinii all share the following characters: short thick flower pedicels barely $1 \mathrm{~cm}$ long; a calyx with 2 primary lobes in the bud that may separate into 3-5 lobes; a typically white, glabrous corolla with a distinctive yellow-orange patch on the lip that continues down into the corolla tube; also additionally, an anther appendage with a short acute-conical projection on the dorsal side (Figs. 2b, 3b). Furthermore, as with the Peninsular Malaysia, Sabah and Philippine records, the ecological distribution of the taxa here included into C. scortechinii is clearly montane: the Thai records were from 1200 to $1655 \mathrm{~m}$, the Laos record was from $953 \mathrm{~m}$, the Vietnam record from $642 \mathrm{~m}$ at Bi Doup in the Central Mountains Region (Parnell et al. 2014), and the Chinese account generally recorded $1500-2000 \mathrm{~m}$ for the species (as ' $C$. hookeri') (Zhang and Tzvelev 1998).

\section{A corollary by way of conclusion: Christisonia vs Aeginetia}

Our current understanding of how the calyx structure varies within $C$. scortechinii allows us to recognise it as a species with the main part of its range from the Malay Peninsula to parts of Thailand, Vietnam, Laos and south China, and which is now recorded for Borneo (Sabah) and probably found also in the Philippines. We thus interpret the species to be vicariant across the South China Sea, between mainland Southeast Asia and the Philippine islands and Borneo. Correspondingly, C. sinensis and $C$. wightii should be regarded as synonyms of $S$. scortechinii:

Christisonia scortechinii Prain (1904: 205); Ridley (1923: 489); Henderson (1954: 335); Parnell et al. (2014: 16-23). Type: MALAY PENINSULA, Perak, no date, Scortechini 2121 (holotype CAL, barcode 0000025048; possible isotype K, barcode K000899781).

Synonyms:

Christisonia wightii Elmer (1915: 2793). Type: PHILIPPINES, Negros, Oriental, Dumaguete (Cuernos Mountains), Mar. 1908, Elmer 9510 (holotype PNH, not found, probably destroyed). 
Christisonia sinensis Beck (1930: 314). Type: CHINA, Yunnan, 2850 m, 31 Jul. 1916, Handel-Mazzetti 9595 (holotype WU, barcode WU0060576).

Christisonia hookeri sensu Zhang and Tzvelev (1998: 242), non Hooker (1885).

It was perhaps unfortunate that Prain (1904) had chosen the term "spathaceous" to describe the calyx of C. scortechinii. Use of this term has also led to some concern that an initially "spathaceous" calyx in C. scortechinii, the sole example of this in a genus where generally the species were described as having several (up to 5) discrete calyx lobes, would weaken the distinction between Christisonia and Aeginetia by their otherwise different calyx forms.

In fact, in C. scortechinii the two primary calyx lobes (which may remain intact or further tear to give more lobes) are subequal and so ensheath the emerging corolla tube at the beginning; this character is therefore rather different from the conspicuously spathaceous calyx in Aeginetia. In Aeginetia, there is only one (incomplete) split developing along the ventral median in the conspicuously curved calyx, through which the corolla emerges. Thus, the genera Aeginetia and Christisonia are still readily distinguished from their calyx form and the way it ruptures during floral development. We venture a distinction between these two otherwise very closely related genera as follows:

(1a) Flower buds covered in a translucent jelly-like slime; flowers typically on short pedicels borne on short or obscure stems that do not protrude much above ground; calyx not or only slightly curved, with 2 -several distinct primary lobes, if only 2 then the lobes subequal but possibly dividing further through apical tears; corollas largely white outside, sometimes infused with pink or blue-violet to various degrees ..... Christisonia

(1b) Flower buds without a slimy covering; flowers carried on taller stems typically $10-40 \mathrm{~cm}$ above ground level; calyx markedly curved or unequally distended, developing only a single split along the ventral median and therefore effectively without distinct lobes; corollas lilac, purple, pink, red or yellow, less frequently white ..... Aeginetia

\section{Authors' contributions}

AVDE collected and photographed specimen material from Kinabalu Park and Peninsular Malaysia, and compiled the information on vegetation, habitat and host plants. KMW conducted the morphological studies and taxonomic comparisons, and initiated the manuscript draft. Both authors read and approved the final manuscript.

\section{Author details}

${ }^{1}$ Centre for Mined Land Rehabilitation, Sustainable Minerals Institute, The University of Queensland, St. Lucia, QLD 4072, Australia. ${ }^{2}$ Laboratoire Sols et Environnement, Université de Lorraine-INRA, UMR 1120, 54000 Nancy, France. ${ }^{3}$ Singapore Botanic Gardens, 1 Cluny Road, Singapore 259569, Singapore.

\section{Acknowledgements}

We thank Sabah Parks, especially Dr Jamili Nais and Rimi Repin, for research support and for the loan of the herbarium material. AVDE is grateful to Rositti Karim and Sukaibin Sumail for help during the fieldwork in Kinabalu Park, and Anthea Phillipps for an earlier identification of Christisonia. KMW acknowledges the support of the National Parks Board, Singapore and the Singapore Botanic Gardens.

\section{Compliance with ethical guidelines}

\section{Competing interests}

The authors declare that they have no competing interests.

Received: 8 September 2015 Accepted: 24 September 2015

Published online: 05 October 2015

\section{References}

Barlow HS (1982) A note on Christisonia scortechinii, a parasitic flowering plant of the Broom-Rape family (Orobanchaceae). Malay Nat J 36:140

Beaman JH (2005) Mount Kinabalu: Hotspot of plant diversity in Borneo. Biol Skr 55:103-127

Beaman JH, Anderson C (2004) The Plants of Mount Kinabalu. 5. Dicotyledon Families Magnoliaceae to Winteraceae. Natural History Publications (Borneo), Kota Kinabalu

Beaman JH, Beaman RS (1990) Diversity and distribution patterns in the flora of Mount Kinabalu. In: Baas P, Kalkman K, Geesink R (eds) The Plant Diversity of Malesia. luwer Academic Publishers: Dordrecht, The Netherlands

Beck von Mannagetta G (1930) Orobanchaceae. In: Engler A (ed) Das Pflanzenreich. regni vegetabilis conspectus, vol. 261, Part 96. W Engelmann, Leipzig

Benniamin A, Chaturvedi SK, Dey S, Moaakum (2012) Supplements to the root parasitic plant in India. A new recorded species Christisonia siamensis Craib (Orobanchaceae). Taiwania 57: 217-221

Elmer ADE (1915) Two Hundred Twenty Six New Species-II. Leafl Philipp Bot 8:2719-2884

Henderson MR (1954) Malayan wild flowers. Malay Nat Soc, Kuala Lumpur

Hooker JD (1885) Orobanchaceae. Flora of British India, vol 4. L. Reeve \& Company, London, pp 319-328

Kiew R (2003) Kinabalu diary and orchid determinations. C.E. Carr's Kinabalu field diary. Gardenwise 20:8-12

Kusano S (1903) Notes on Aeginetia indica. Linn Bot Mag 17:81-84

Lee A, Goseco F (1932) Studies of the sugar-cane root parasite Aeginetia indica. Int Soc Sugar Cane Tech Congr San Juan Bull 101:1-12

McNeal JR, Bennett JR, Wolfe AD, Mathews S (2013) Phylogeny and origins of holoparasitism in Orobanchaceae. Am J Bot 100:971-983

Nandikar M, Singh R, Gurav R, Shinde R (2013) Lectotypification and notes on the identity of Christisonia calcarata (Orobanchaceae). Rheedea 23:26-29

Parnell J (2001) A revision of Orobanchaceae in Thailand. Thai For Bull (Bot) 29:72-80

Parnell J (2008) Orobanchaceae. In: Santisuk T, Larsen K (eds) Flora of Thailand, vol 9(2). The Forest Herbarium, National Park, Wildlife and Conservation Department, Bangkok, pp 142-147

Parnell J (2012) Aeginetia flava: a new and remarkable species of Aeginetia: Orobanchaceae from South-eastern Thailand. Kew Bull 67:81-84

Parnell J, Strijk JS, Maknoi C, Luu HT, Pooma R, Sirimongkol S, Rueangruea S, Tichai W, Ritphet N (2014) New records expand the ranges of Christisonia siamensis and Christisonia scortechinii, the latter species being new to Thailand. Thai For Bull (Bot) 42:16-23

Prain D (1904) Noviciae Indicae XXIV. Some new Indian plants. J As Soc Bengal 73(II, Natural History): 192-206

Proctor J (2003) Vegetation and soil and plant chemistry on ultramafic rocks in the tropical Far East. Perspect Plant Ecol Evol Syst 6:105-124

Quisumbing E (1940) On Christisonia wightii, Elmer, a parasite of sugarcane. Philipp J Plant Ind 11:397-400

Ridley HN (1923) The Flora of the Malay Peninsula: Gamopetalae, vol II. L. Reeve \& Co., London

Tan Y-H (2013) Christisonia siamensis Craib, a newly recorded species of Christisonia (Orobanchaceae) from China. Guihaia 33:521-522 
Thiers B (2015). Index Herbariorum: a global directory of public herbaria and associated staff. New York Botanical Garden's Virtual Herbarium. Available from: http://sweetgum.nybg.org/ih/. Accessed 1 July 2015 (continuously updated)

Trimen H (1893-1898). Plates in Illustration of A Hand-Book to the Flora of Ceylon. Dulau \& Co., London

Trimen H (1895) A Hand-Book to the Flora of Ceylon, vol 3. Dulau \& Co., London

Van der Ent A, Repin R, Sugau J, Wong KM (2014) The Ultramafic Flora of Sabah. An introduction to the plant diversity on ultramafic soils. Natural History Publications (Borneo). Kota Kinabalu
Van der Ent A, Repin R, Sugau J, Wong KM (2015) Plant diversity and ecology of ultramafic outcrops in Sabah (Malaysia). Aust J Bot 63:204-215

Van Steenis CGGJ (1967) Miscellaneous botanical notes XVIII. Blumea 15:145-155

Wong KM (1998) Patterns of plant endemism and rarity in Borneo and the Malay Peninsula. In: Peng C-I, Lowry PP II (eds) Rare, Threatened and Endangered Floras of Asia and the Pacific Rim. Institute of Botany, Taiwan Yong HS (1989) Colour polymorphism in the flowers of the parasitic plant Malayan Bamboorape (Christisonia scortechinii). Nat Malays 14:100-103

Zhang Z-Y, Tzvelev NN (1998) Orobanchaceae. Flora of China vol 18. Science Press, Beijing \& Missouri Botanical Garden, St. Louis, pp 229-243

\section{Submit your manuscript to a SpringerOpen ${ }^{\odot}$ journal and benefit from:}

- Convenient online submission

- Rigorous peer review

- Immediate publication on acceptance

- Open access: articles freely available online

- High visibility within the field

- Retaining the copyright to your article

Submit your next manuscript at $>$ springeropen.com 